\title{
Dental Health Evaluation of Children in Kosovo
}

\author{
Agim Begzatia \\ Kastriot Meqab \\ David Siegenthaler ${ }^{c}$ \\ Merita Berishad \\ Walter Mautsche
}

\section{ABSTRACT}

Objectives: The aim of this study was to assess caries prevalence of preschool and school children in Kosovo.

Methods: The assessment, which was carried out between 2002 and 2005, included measurements of early childhood caries, deft and DMFT.

Results: In total, 1,237 preschool and 2,556 school children were examined. The mean deft of preschool children was 5.9, and the mean DMFT of school children aged 12 was 5.8. The caries prevalence for 2- to 6-year-old preschool children was $91.2 \%$, and the prevalence for 7- to 14-yearold school children was $94.4 \%$. The prevalence of early childhood caries was $17.6 \%$, with a mean deft of 10.6 .

Conclusions: All data assessed showed the very poor oral health status of children in Kosovo. Interviews with children and teachers indicated poor knowledge regarding oral health. Significant measures must be taken to improve this situation. (Eur J Dent 2011;5:32-39)

Key words: Caries prevalence; deft/DMFT; Preschool children; School children; Prevention.

a Assistant Professor, DDS, PhD, Department of Pedodontics and Preventive Dentistry, Dentistry School, Medical Faculty, University of Prishtina, Prishtina, Kosovo.

b Assistant, Mr Sc Dent, Department of Periodontology and Oral Medicine, Dentistry School, Medical Faculty, University of Prishtina, Prishtina, Kosovo.

Private Practice, Dr. med. dent., 8032 Zürich, Switzerland.

d Associate Professor, MD, PhD, National Institute of Public Health, Department of Statistic, Medical Faculty, University of Prishtina, Prishtina, Kosovo.

e Med. dent., MSc (DPH), Department of Prosthodontics, University of Aachen, Germany.

- Corresponding author: Agim Begzati

Department of Pedodontic and

Preventive Dentistry, School of Dentistry,

Medical Faculty, University of Prishtina,

Prishtina, Republic of Kosovo.

Phone: +38138512474

E-mail: agimbegzatidyahoo.com

\section{INTRODUCTION}

In 2000, the total resident population of Kosovo was estimated to be 2 million inhabitants, ${ }^{1}$ with $32.8 \%$ of the population aged 14 years or less. ${ }^{2}$ After the war in Kosovo in 1999, returning refugees' first priorities were housing and economic issues. The initial phase of reorganization in healthcare and educational institutions did not emphasize oral health promotion. Currently, Kosovo has an underdeveloped economy and rather poor educational and health systems. Basic education still does not include training in oral health. The health system generally focuses on intervention and neglects issues such as preventive dentistry.

Despite difficulties associated with implementing measures in preventive dentistry, the Department of Preventive Dentistry at the Dental Clinic of the University of Prishtina founded a study group 
emphasizing oral health promotion. The group was supported by the non-governmental organizations, including MEDAIR, the Finnish Red Cross, the Danish Red Cross, and Dental Health International Netherlands (DHIN). The aim of the group is to promote oral health by re-establishing oral health education for school and preschool children in Kosovo.

Pediatric dentists have advocated early oral examinations, appropriate interventions and parental counseling, ${ }^{3}$ but these have not been carried out systematically in Kosovo. Similarly, the majority of preschool-age children have never been to a dentist. ${ }^{4}$

The majority of children visit dentists only in the case of acute pain and never on the basis of preventive measures.

One of the most aggressive types of caries in preschool children is early childhood caries (ECC). It is an acute dental disease that commonly occurs initially in the upper maxillary incisors, with localization in the neck of the tooth and with rapid development that leads to complete destruction of the crown. Due to its characteristic features and etiological factors, ECC is known by a variety of names: caries of incisors, nursing caries, nursing bottle syndrome, baby bottle tooth decay (BBTD), early childhood caries (ECC), severe early childhood caries, and rampant caries (RC). ${ }^{5-11}$

Due to the lack of epidemiological data concerning the oral health status of children in Kosovo, the aims of this study were;

- to assess the prevalence of caries in preschool and school children,

- to assess the prevalence of ECC in preschool children,

- to evaluate the decay status of the children's first permanent molars,

- to evaluate the children's and teacher's levels of knowledge about oral health issues, and

- to make proposals for preventive measures.

\section{MATERIALS AND METHODS}

The sample in the present study consisted of two groups derived from a multi-site examination: preschool and school children. From a total of 3,793 examined children, there were 1,237 preschool children (aged 2 to 6 years old) and 2,556 school children laged 7 to 14 years old). This was a cross-sectional study conducted in randomly se- lected locations in Kosovo. The sample size was calculated with a confidence level of $95 \%$ and a confidence interval of 2 .

The study was specifically based on the deft/ DMFT index, following the recommendations of the World Health Organization. ${ }^{12}$

Preschool children were examined at various kindergartens in Prishtina and Prizren, while school children were examined at various primary schools in Prishtina, Peja, Fushë Kosova, Kastriot and Deçan.

The examinations were done under natural light, using a dental mirror and a probe. It was performed by five dentists from the Prishtina University Dental Clinics, mainly from the Preventive Dentistry Department. The Study Group for Oral Health Promotion conducted the study, and the examiners received relevant training in advance. Diagnostic criteria were calibrated, ${ }^{13}$ with an inter-examiner reliability of kappa $=0.92$ based on the examination of 30 children of different ages.

For the caries assessments, all tooth surfaces were examined. Every defect in the tooth was tested with a probe, and every visual change in the enamel transparency in the early phases of demineralization was defined as a carious lesion. Decayed, filled and extracted/missing (due to caries) teeth were recorded in a modified WHO Oral Health Assessment Form. ${ }^{12}$

DMFT (for permanent dentition) and deft (for primary dentition) describes the number, or the prevalence, of caries in an individual. ${ }^{14}$ DMFT and deft are methods to numerically express the caries experience and are obtained by calculating the number of decayed (D), missing (M) / extracted (e), and filled (F) teeth (T).

The ECC definition and diagnostic criteria have always been very complex. Ismail and Sohn ${ }^{15}$ describe the many different clinical diagnostic criteria of ECC. Based on these studies, we have used the criterion that describes ECC as at least two affected primary maxillary incisors with caries.

\section{Questionnaire}

The interviews were mostly carried out in primary schools and kindergartens in Prishtina, and they incorporated questions concerning children's experiences with oral health and teachers' basic knowledge of oral health. Approximately six months prior to the interviews, lectures were held 
to provide teachers with some information on oral health in the same institutions used in this study. Moreover, there were practical demonstrations of tooth brushing techniques for children, and various printed materials published by the Group le.g. flyers, handouts and manuals) were distributed to the children and the teachers.

The questionnaire for the children was given to 14 primary schools and 7 kindergartens in Prishtina, and it included the following questions:

1. Have you ever been to a dentist (before)?

2. If yes, give the reason for the visit.

3. What is your experience with the dentist?

4. Do you have a dentist at your school?

5. Are there lessons about oral health at your school?

6. How often are sweet foods served in kindergarten?

7. How often do you eat sweet food(s) during the day?

The interviews for the preschool children were done with the help of their mothers or teachers.

To obtain data on the teachers' levels of basic knowledge about oral health issues, some questions were also addressed directly to the teachers. These questions were as follows:

1. When does the eruption of the primary and permanent teeth start?

2. The first permanent molar erupts only once in life (true-false).

3. Describe the tooth structures.

4. Describe the factors of tooth decay.

5. Can sweets be taken between or with meals?

6. How often and how long should teeth be brushed?

7. What is the element that is in toothpaste that protects teeth?

8. When should the dentist be visited?

The levels of knowledge were assessed as poor (0-25\% or $1-2$ correct answers), satisfactory (25\%-
$50 \%$ or $3-4$ correct answers), good $(50 \%-75 \%$ or $5-6$ correct answers) and very good (75\%-100\% or 7-8 correct answers).

\section{Limitations}

This study was carried out in Kosovo, where the significant post-war internal migration from villages to cities is a significant factor. As a result, we were unable to categorize the children by locality (e.g. urban, suburban, or rural). In addition, most of the examined children were from Prishtina, where internal migration has caused a sharp rise in the overall population. Thus, we experienced a heterogeneous structure of the children by locality.

\section{Statistical analysis}

The collected data were entered in Statistical Package for Social Sciences (SPSS 12). The level of statistical significance was set at $\mathrm{P}=0.05$.

\section{RESULTS}

In the sample, $28.6 \%$ of the children were caries-free (deft $=0$ ) at the age of two. As expected, this percentage decreased with increasing age. Only $2.1 \%$ of six-year-old children were cariesfree. The mean deft in preschool children was 5.6. The lowest mean deft was seen in two-year-old children (2.1), while the highest were in five- and six-year-olds (8.1 and 7.9, respectively). Less than one-tenth $(9.8 \%)$ of the examined preschool children had a deft of 0 . In children two years or older, the testing of the differences for gender for the mean deft values showed statistically significant differences for five- and six-year-olds $(P=0.004$ and $P=0.009$, respectively). There was no significant difference between gender for two-, three-, or four-year-olds $(P=0.816, P=0.302$ and $P=0.814$, respectively) (Table 1).

As expected, the mean deft in preschool chil-

Table 1. Caries prevalence, mean deft and comparison of mean deft between gender in preschool children.

\begin{tabular}{|c|c|c|c|c|c|c|}
\hline \multirow{2}{*}{ Age } & \multirow{2}{*}{ Examined } & \multirow{2}{*}{$\operatorname{deft}=0$} & \multicolumn{3}{|c|}{ Mean deft } & \multirow{2}{*}{ P value* } \\
\hline & & & Male & Female & Total & \\
\hline$\leq 2 y$ & 154 & $28.60 \%$ & 2.12 & 2.18 & 2.15 & 0.816 \\
\hline $3 y$ & 283 & $12.40 \%$ & 4.16 & 3.86 & 4.01 & 0.302 \\
\hline $4 y$ & 312 & $9.30 \%$ & 6.01 & 5.93 & 5.97 & 0.814 \\
\hline $5 y$ & 296 & $3.00 \%$ & 8.64 & 7.66 & 8.14 & 0.004 \\
\hline $6 y$ & 192 & $2.10 \%$ & 8.3 & 7.47 & 7.9 & 0.009 \\
\hline Total & 1237 & $9.80 \%$ & 6.1 & 5.65 & 5.86 & 0.024 \\
\hline
\end{tabular}


dren increased with age, with significant statistical differences between adjacent age groups (twoyear-olds vs. three-year-olds, three-year-olds vs. four-year-olds, and four-year-olds vs. $-\mathrm{P}<.001$ ), except between five-year-olds and six-year-olds (P>.05). An ANOVA test showed statistical differences between all of the age groups ( $F=204.59$, $P<$.001) (Table 2).

The greatest contribution to the deft index was untreated caries, which varied from 2.04 for twoyear-olds to 6.37 for five-year-olds. Six-year-old children showed a slight decrease (6.09) (Table 3).

The 1,237 examined preschool children revealed an early childhood caries (ECC) prevalence of $17.6 \%$ (179 children). The mean deft value for children with ECC was 10.6 (Table 4).

Even though boys had a higher ECC prevalence, we did not find any statistically significant differences in the ECC prevalence between genders ( $T$-test $=1.664, p=0.096$ ).

The percentage of caries-free children (DMFT $=0$ ) at the age of six was $13.3 \%$, and as ex-

Table 2. Testing of mean deft between adjacent age groups.

\begin{tabular}{ll}
\hline 2y vs. $3 y$ & $P<.001$ \\
3y vs. $4 y$ & $P<.001$ \\
4y vs. $5 y$ & $P<.001$ \\
$5 y$ vs. 6y & $P>05$ \\
\hline ANOVA, F=204.59, P<.001 & \\
\hline
\end{tabular}

pected, this decreased with increasing age. At 14 years old, only $0.9 \%$ were caries-free. The mean DMFT index was 4.86 for all school children. The increase in the mean DMFT was related to age, increasing from 2.36 for 7-year-olds to 6.91 for 14-year-olds. There was no significant difference between the genders for any age group (Table 5).

The mean DMFT of school children increased with age, with a statistically significant difference between the age groups tested with ANOVA ( $F=290.83, P<.001)$.

The differences between adjacent age groups showed a difference for 7-year-olds vs. 8-yearolds, 9-year-olds vs. 10-year-olds, 10-year-olds vs. 11-year-olds, 11-year-olds vs. 12-year-olds, and 12-year-olds vs. 13-year-olds ( $\mathrm{P}<$.0001). There was no difference for 8 -year-olds vs. 9-year-olds $(P>$.05) or 13-year-olds vs. 14-year-olds ( $P>.05)$ (Table 6).

The greatest contribution to the DMFT index was untreated caries, which varied from 2.10 for 7-year-olds to 5.00 for 14-year-olds (Table 7).

First permanent molars were the most decayed teeth with a high prevalence (97\%). The DMFT index related to the first permanent molar was 3 , where $82.4 \%$ were decayed, $8.3 \%$ lost due to decay, and only $9.3 \%$ were treated (Table 8).

The interview involved 446 school children and 418 preschool children (with the help of the parents or teachers). The results from the question-

Table 3. The deft structure of preschool children

\begin{tabular}{|c|c|c|c|c|c|}
\hline Age & Examined & d & e & $f$ & deft \\
\hline$\leq 2 y$ & 154 & 2.04 & 0.11 & 0 & 2.15 \\
\hline $3 y$ & 283 & 3.72 & 0.19 & 0.1 & 4.01 \\
\hline $4 y$ & 312 & 5.3 & 0.43 & 0.2 & 5.97 \\
\hline $5 y$ & 296 & 6.37 & 1.62 & 0.15 & 8.14 \\
\hline $6 y$ & 192 & 6.09 & 1.71 & 0.11 & 7.91 \\
\hline Total & 1237 & 4.91 & 0.82 & 0.13 & 5.87 \\
\hline
\end{tabular}

Table 4. ECC prevalence by gender in preschool children and its comparison.

\begin{tabular}{|c|c|c|c|c|c|c|}
\hline \multicolumn{7}{|c|}{ ECC prevalence } \\
\hline & & Examined children & & ECC prevalence & & T-test \\
\hline Gender & $\mathrm{N}$ & $\begin{array}{c}\text { Children with } \\
\text { deft }>0\end{array}$ & $\begin{array}{c}\text { Children with } \\
\text { ECC }\end{array}$ & $\begin{array}{l}\text { for examined } \\
\text { children }\end{array}$ & Mean deft $\pm S D$ & \\
\hline M & 625 & 505 & 93 & $18.40 \%$ & $10.8 \pm 3.2$ & $\mathrm{~T}=1.664$ \\
\hline $\mathrm{F}$ & 612 & 512 & 86 & $16.80 \%$ & $10.5 \pm 3.2$ & $P=0.096$ \\
\hline $\mathrm{T}$ & $1237^{*}$ & 1017 & 179 & $17.60 \%$ & $10.6 \pm 3.2$ & \\
\hline
\end{tabular}

*: P value between gender. 
naire showed that $73 \%$ of the children have had a dental visit at least once in their lifetime. The most common reason for that visit was a toothache (69\%), and $66 \%$ of the children had a bad experience while visiting the dentist. Oral health classes were not organized at any of the schools, even in those with existing dental offices. Concerning the consumption of sweets, $58 \%$ of the children responded that they consumed sweet snacks at least twice a day. Those children who received meals in kindergarten had sweet food once a day.

A questionnaire was filled out by 217 teachers in nine schools. The results from the questionnaire for the teachers showed that $54 \%$ of them had poor, $39 \%$ had satisfying and $7 \%$ had good knowledge on basic oral health issues. Based on the answers, approximately $30 \%$ thought that the "first molar" was the tooth that gets replaced by an adult tooth. Nearly $75 \%$ thought that children should visit the dentist only when they have a complaint. More than $50 \%$ did not know about the benefits of fluoride in dental health. Approximately $65 \%$ of the teachers thought that sweets can be consumed in between meals.

\section{DISCUSSION}

The data from this oral health assessment of children of Kosovo showed a very low level of dental health in both the primary and permanent dentitions. Caries prevalence expressed via the DMFT index was very high. The results from the present study show that dental health of these children in Kosovo is worse than that of children in other European countries. Specifically, the mean deft for five-year-olds at preschools in Kosovo (8.1) was found to be higher than the same value for preschool children in USA (1.7) and in many other European countries (1991-1995), including Ireland (0.9), Spain (1.0), Denmark (1.3), Norway (1.4), Finland (1.4), Netherlands (1.7), United Kingdom (2.0), France (2.5), and Germany (2.5). Our results are only comparable to the rates in $\mathrm{Be}$ larus (7.4), Sarajevo, Bosnia (7.53) (ages 5-7) and Albania (8.5). ${ }^{16,17}$ The low treatment rate for children in Kosovo $(<2 \%)$ indicates a high treatment need. Also, the mean DMFT (5.8) of school children in Kosovo (age 12) was higher in comparison with school children (age 12) of the following developed countries: Netherlands (1.1), Finland (1.2), Denmark (1.3), USA (1.4), United Kingdom (1.4), Sweden (1.5), Norway (2.1), Ireland (2.1), Germany (2.6) and Croatia (2.6) (16). The mean DMFT of Kosovo's children (age 12) was similar to the mean values in Latvia (7.7), Poland (5.1) and a group of 12- to 14-year-olds in Sarajevo, Bosnia (7.18). ${ }^{16,17}$ As previously mentioned, the low treatment rate of the children in Kosovo is unfavorable and indicates a high treatment need.

The pathology with the most severe consequences for children's dental health was found to be ECC, with a high prevalence (17.6\% of children). The ECC prevalence of children in Kosovo is higher than the prevalence in children in developed western countries, which is less than $5 \%$. $^{18,19}$ The mean deft of Kosovo's children with ECC was 10.6. The clinical course of ECC is manifested initially with "white spot" lesions, with a rapid development until complete destruction of the crown. De Grauwe

Table 5. Caries prevalence, mean DMFT and comparison of mean DMFT between genders in school children

\begin{tabular}{|c|c|c|c|c|c|c|}
\hline \multirow{3}{*}{ Age } & \multirow{3}{*}{ Examined } & \multicolumn{4}{|c|}{ Mean DMFT } & \multirow{3}{*}{ P value* } \\
\hline & & DMFT $=0$ & & & & \\
\hline & & & M & $\mathrm{F}$ & $T$ & \\
\hline $7 y$ & 330 & $13.30 \%$ & 2.45 & 2.27 & 2.36 & 0.188 \\
\hline $8 y$ & 212 & $8.50 \%$ & 3.19 & 3.42 & 3.30 & 0.277 \\
\hline $9 y$ & 201 & $6.50 \%$ & 3.78 & 3.62 & 3.70 & 0.405 \\
\hline $10 y$ & 383 & $6.00 \%$ & 4.18 & 4.44 & 4.31 & 0.148 \\
\hline $11 y$ & 411 & $5.10 \%$ & 4.80 & 5.01 & 4.91 & 0.211 \\
\hline $12 y$ & 343 & $3.50 \%$ & 5.75 & 5.88 & 5.81 & 0.431 \\
\hline $13 y$ & 464 & $2.20 \%$ & 6.48 & 6.74 & 6.61 & 0.110 \\
\hline $14 y$ & 212 & $0.90 \%$ & 7.19 & 6.63 & 6.91 & 0.055 \\
\hline Total & 2556 & $5.60 \%$ & 4.83 & 4.88 & 4.86 & 0.167 \\
\hline
\end{tabular}

*: P value between gender. 
described the development of ECC and found that the progression of the lesion from the enamel to the dentin occurs within six months. ${ }^{20}$

It is now well understood that ECC is a multifactorial disease, with numerous biological, psychosocial and behavioral risk factors. ${ }^{21,22}$ One of the important risk factors in the etiology of ECC is bottle feeding, especially during the night. Kaste found that $95 \%$ of children worldwide aged 6 months to 5 years had used a bottle. ${ }^{23}$

Bacteria play an important role in the contagious nature of ECC (S. mutans) and is naturally a subject of many studies in the field of dentistry. ${ }^{24}$

As a measure of ECC prevention, the education of parents regarding the dangers of inappropriate feeding practices on the oral health of their children is considered to be an important issue. ${ }^{25}$ Considering the complexity of factors associated with

Table 6. Testing of mean DMFT between adjacent age groups.

\begin{tabular}{ll}
\hline 7y vs. $8 y$ & $P<.001$ \\
$8 y$ vs. 9y & $P>.05$ \\
9y vs. 10y & $P<.001$ \\
10y vs. 11y & $P<.001$ \\
11y vs. 12y & $P<.001$ \\
12y vs. 13y & $P<.001$ \\
13y vs. 14y & $P>.05$ \\
\hline
\end{tabular}

ANOVA, $F=290.83 . P<.001$

Table 7. The DMFT structure of school children.

\begin{tabular}{|c|c|c|c|c|c|}
\hline Age & Examined & D & $M$ & $\mathrm{~F}$ & DMF \\
\hline $7 y$ & 330 & 2.10 & 0.16 & 0.10 & 2.36 \\
\hline $8 y$ & 212 & 2.90 & 0.30 & 0.10 & 3.30 \\
\hline $9 y$ & 201 & 3.30 & 0.20 & 0.20 & 3.70 \\
\hline $10 y$ & 383 & 3.40 & 0.40 & 0.51 & 4.31 \\
\hline $11 y$ & 411 & 4.00 & 0.51 & 0.40 & 4.91 \\
\hline $12 y$ & 343 & 3.96 & 0.90 & 0.96 & 5.81 \\
\hline $13 y$ & 464 & 4.91 & 0.80 & 0.90 & 6.61 \\
\hline $14 y$ & 212 & 5.00 & 0.90 & 1.01 & 6.91 \\
\hline Total & 2556 & 3.76 & 0.54 & 0.55 & 4.86 \\
\hline
\end{tabular}

Table 8. Caries prevalence and DMFT structure for first permanent molar (M1).

\begin{tabular}{lccc}
\hline Mean DMFT & Decayed (D) & Missing (M) & Filled (F) \\
\hline 3 & 2.47 & 0.25 & 0.28 \\
& $82.40 \%$ & $8.30 \%$ & $9.30 \%$ \\
Caries prevalence $97.0 \%$ & & & \\
\hline
\end{tabular}

ECC, it is unfortunate that most of the interest in this problem is limited to dental organizations. The critical change needed to accomplish the necessary research on the prevention of ECC may be to expand the network by including other health professionals, community leaders, national organizations serving children and political leaders. ${ }^{26}$

Another interesting finding is the lack of awareness of the first permanent molar. In our daily activities in the pediatric dentistry department, more than one-third of all dental treatment rendered is focused on the first permanent molar. The lack of educational measures leads to a high morbidity of this important tooth. Often, parents believe that the first permanent molar belongs to the primary dentition and will subsequently be replaced.

The most common reason that children visit the dentist was a toothache. There were only a small number of children who visited to a dentist prior to pain. A regular recall and check-up was rarely reported. Usually, children were accompanied by their parents. Their first comments regarding their dental visit were "my child a terrible toothache all night" and "we couldn't sleep at all." The children with toothaches had bad experiences at the dentist and thus refused future visits. Even though there were dental offices in some of the schools in this study, they were often dysfunctional and poorly equipped. Often, there were no dentists specializing in the fields of pedodontics 
or preventive dentistry. Many of the dentists employed were trained in other fields le.g., prosthetics or oral surgeryl or simply inexperienced. In the school dental offices, pain relief measures were often provided, but no preventive program or educative measures were undertaken. Lessons about oral health were scarce. There were no subjects in the primary school curricula dealing with issues in oral health.

There were no dental offices in any of the kindergartens. A greater awareness by the teaching staff was only with regard to tooth brushing instructions. In none of the schools did we find any intention to reduce sweet meals during the day or to cease bottle-feeding.

There was a shortage in the teachers' knowledge of basic oral and dental health issues. They were unaware of the chronology of tooth eruption, often providing answers that the "first molar" will be replaced. Unfortunately, most of them thought that children should visit the dentist only when experiencing a complaint. More than half did not know anything about the benefits of fluoride in dental health. About two-thirds of the teachers were unaware of dangers that sweets can pose when they are used in between meals. But there was a general agreement that school curricula should include topics concerning general and oral health. Basic interest in this subject did exist, but oral health promotion was largely negligible due to the high priority of other issues, including mine awareness, coping with war trauma and very low income levels.

Because of the lack of active preventive measures in Kosovo, we propose to continue educational measures.

The following health educational measures can serve as an effective foundation for raising awareness of oral health:

- The training of dentists and other dental healthcare personnel to manage preventive programs for early childhood patients.

- Oral health promotion training for kindergarten and school teachers.

- Cooperation with the Ministry of Health and the Ministry of Education regarding the development of teaching curricula that includes oral health topics.

- The introduction of regular tooth brushing practices in kindergartens and schools.
- Planned active preventive programs in schools with existing dental clinics, such as

- practical demonstrations of oral health maintenance,

- dental plaque detection and its removal,

- topical fluoride application,

- fissure sealing procedures,

- treatment of early stages caries.

\section{CONCLUSIONS}

- The dental health of preschool and school children in Kosovo, as measured by deft and DMFT indices, was severely lacking.

- The index values in preschool children were very high with maximum values seen in five-yearolds (mean deft of 8.1). On average, these children had almost five teeth with untreated caries.

- The index values in school children were also very high, with maximum values in the fourteenyear-olds (mean DMFT of 6.91). On average, these children had almost five teeth with untreated caries.

- Kosovo's children exhibited high ECC values $(17.6 \%$ of all examined children), with a mean deft of 10.6 .

- The first permanent molar was the most affected tooth in the permanent dentition; the mean DMFT for this tooth was 3.00.

- Children's knowledge and awareness of oral health issues was very low.

- The testing of teachers showed that most had limited knowledge regarding oral health, and they failed to serve as useful resources for education on this issue.

\section{ACKNOWLEDGEMENTS}

The authors are most grateful to the children, mothers and teachers who participated in this study as well as the other staff at the kindergartens and schools. We acknowledge the financial support of MEDAIR, SSO and DHIN during our oral health promotion activities.

\section{REFERENCES}

1. Demographic, social, economic situation and reproductive health in Kosovo following the 1999 conflict. Results of a household survey, November 1999- February 2000. January 2001. http://www.unfpakos.org/documents/DHS2000. pdf. accessed on October $15^{\text {th }}, 2009$ 
2. Kosovo and its Population. Statistical Office of Kosova, September 2003, revised version. http://www.ecmi.de/ emap/download/KosovoStatisticsFinalOne.pdf, accessed on October $15^{\text {th }}, 2009$

3. Nowak AJ. Rationale for the timing of the first oral evaluation. Pediatric Dent 1997;19:8-21.

4. Waldman HB. Preschool children-need and use of dental services. Dent Clin North Am 1995;39:887-896.

5. Ripa LW. Nursing caries: a comprehensive review. Pediatr Dent 1988; 10:268-282

6. Derkson GD, Ponti P. Nursing bottle syndrome: prevalence end etiology in a non fluoridated city. J Can Dent Assoc 1982;48:389-393.

7. Arkin EB. The Healthy Mothers, Healthy Babies Coalition: four years progress. Public Health Rep 1986;101:147-156.

8. Fass EN. Is bottle feeding of milk a factor in dental caries? J Dent Child 1962;29:245-251.

9. Drury ThF, Horowitz AM, Ismail Al, Maertens MP, Rozier RG, Selwitz RH. Diagnosing and reporting early childhood caries for research purposes. J Public Health Dent 1999;59:192-197.

10. Horowitz HS. Research issues in early childhood caries. Community Dent Oral Epidemiol 1998;26(Suppl 1):67-81.

11. Centers for Disease Control and Prevention (CDCP), Conference. Atlanta, GA, September 1994.

12. World Health Organization: Oral Health surveys. Basic Methods (4 $4^{\text {th }}$ ed.). Geneva: World Health Organization; 1997.

13. Hunt RJ. Percent agreement, Pearson's correlation, and kappa as measures of inter-examiner reliability. J Dent Res 1986;65:128-130.

14. http://www.whocollab.od.mah.se/expl/orhdmft.html; retrieved on October $12^{\text {th }}, 2009$.

15. Ismail Al, Sohn W. A systematic review of clinical diagnostic criteria of early childhood caries. J Public Health Dent 1999;59:171-191.

16. Marthaler M, O'Mullane M, Vrbic V. The prevalence of dental caries in Europe 1990-1995. Caries Res 1996;30:237-255.

17. Kobaslia S, Maglaic N, Begovic A. Caries prevalence of Sarajevo children. Acta Stomatologica Croatica 2000;34:83-85.

18. Kaste LM, Selwitz RH, Oldakowski RJ, Brunelle JA, Win DM, Brown LJ. Coronal caries in the primary and permanent dentition of children and adolescent 1-17 years of age: United States,1988-1991. J Dent Res 1996;75:631-641.

19. Winter GB, Hamilton MC, James PMC. Role of comforte as an aetiological factor in rampant caries of deciduous dention. Arch Dis Child 1966;417:207-212.

20. De Grauwe A, Aps JK, Martens LC. Early Childhood Caries (ECC): What's in a name? Europ J Paediatric Dent 2004;5:6270.

\section{January 2011 - Vol.5}

21. Wyne AH. Early childhood caries: nomenclature and case definition. Community Dent Oral Epidemiol 1999;27:313-315.

22. Seow WK. Biological mechanisms of early childhood caries. Community Dent Oral Epidemiol 1998;26(Suppl. 1):49-61.

23. Kaste LM, Selwitz RH. Inappropriate infant bottle feeding. Status of the Health People 2000 objective. Arch Pediatr Adolesc Med 1995;149:786-791.

24. Berkowitz RJ. Etiology of nursing Caries: a microbiologic perspective. J Public Health Dent 1996;56:51-54.

25. Horowitz HS: Research issues in early childhood caries. Community Dent Oral Epidemiol 1998;26(Suppl. 1):67-68.

26. Ismail Al. Prevention of early childhood caries. Community Dent Oral Epidemiol 1998;26:Supplement 1:49-61. 